\title{
Guerra Fría y Cine
}

\author{
EDUARDO ALONSO FRANCH \\ Universidad de Valladolid
}

\begin{abstract}
Resumen
El artículo trata sobre las relaciones entre dos temas como la Guerra Fría y el cine. Se abordan cuestiones como la historia de las relaciones entre Estados Unidos y la Unión Soviética, la "caza de brujas" en Hollywood, la evolución en la representación de los comunistas en la pantalla: desde las películas prosoviéticas de la Segunda Guerra Mundial a la percepción del peligro nuclear y militar del antiguo aliado.

Destacan en este artículo los capítulos dedicados a personajes como el cineasta Oliver Stone y su obra, el escritor y guionista Graham Greene, el nuevo cine polaco y la figura de Andrzej Wajda, las ciudades (Moscú, Berlín, Praga...) y su plasmación en las películas de la época, los espías y su mundo, la URSS y la Guerra Fría. También se aborda la relación entre la España franquista y el cine de la época, con el comienzo de las grandes superproducciones y la llegada de Ava Gardner y Frank Sinatra a la Península Ibérica, la imagen de los norteamericanos en Bienvenido, Mister Marshall.
\end{abstract}

\begin{abstract}
The Article take the Relations between two Topics as the Cold War and the Cinema. It is take Questions as the United States and the Soviet Union, the "Hunting of Witchs" in Hollywood, the Evolution in the Representation of the Communists in the Screen: from the pro - Soviet Movies of the Second World War to the Perception of the nuclear and military Danger of the former Allied.

It is emphasized in this Article the Chapters dedicated to Personages as the Director Oliver Stone and his Work, the Writer and Scriptwriter Graham Greene, the New Polish Cinema and the Personality of Andrzej Wajda, the Cities (Moscow, Berlin, Prague...) and his Shape in the Movies of the Time, the Spies and his World, the URSS and the Cold War... Also, it is treated the Relation of the Franco's Spain and the Cinema of the Time, with the Start of the big Overproductions and the Advent of Ava Gardner and Frank Sinatra to the Iberian Peninsula, the Image of the Northamericans in Bienvenido, mister Marshall!...
\end{abstract}

\section{Introducción histórica}

La Guerra Fría abarcó un largo período de tiempo en el siglo XX y a veces rebrota con intensidad en el mismo siglo XXI. A partir de 1945, con el acceso de 
Truman a la presidencia de los Estados Unidos y la consecución de la bomba atómica por parte de los Estados Unidos, las buenas relaciones entre ambas potencias en la época de Roosevelt, que culminaron con la intervención norteamericana en la SGM, se transformaron en rabiosa persecución de todo lo sospechoso de izquierdista en la política, las artes y el cine en particular. Se pasó de un cine benevolente o incluso favorable al aliado de antaño a una producción paranoica y con fuertes implicaciones de crítica - a veces ridícula - de las posiciones de la URSS. Poco a poco, las fuertes tensiones derivadas de la Guerra de Corea y la derrota norteamericana en Vietnam acabaron derivando en un conocimiento mayor del adversario, juzgado siempre como el enemigo a batir. Un punto decisivo en el balance histórico de la Guerra Fría fue sin duda la época de Ronald Reagan / George Bush senior y Mijaíl Gorbachov en la Unión Soviética, que terminó con la desaparición de la URSS, el final del Muro de Berlín y la reunificación de Alemania y el consiguiente desnivel entre las fuerzas capitalistas occidentales y el fragmentado espacio político de la Europa socialista del centro y este de Europa. El cine de espías refleja esta época y la anterior, con cierto maniqueísmo en la elección de buenos y malos, que generalmente han sido los soviéticos. El peligro nuclear, obsesión permanente del cine de la época, ha dado paso al tema de la obsolescencia de centrales como Chernobyl y su incidencia en la vida de las regiones ucranianas afectadas. Aunque las tensiones entre la OTAN y los aliados de la Rusia post - soviética no hayan desaparecido, pese a la eventual alianza entre Donald Trump y Vladimir Putin. Para el futuro queda tal vez el análisis en la pantalla de la vida y obra de personalidades como Assange o Snowden, analistas que han arriesgado su carrera y su libertad pasando al enemigo o divulgando información privilegiada sobre las maniobras encubiertas de las agencias norteamericanas y sus peligros para la paz y la libertad en el planeta Tierra.

\section{Las películas de la Guerra Fría}

La caza de brujas del maccarthysmo por la que se investiga a guionistas, directores y otros cineastas de Hollywood ha quedado plasmada en varias películas. Complementariamente, hay algunas comedias que, al final del ciclo, ponen en cuestión el equilibrio de terror propio de la Guerra Fría ${ }^{1}$.

Entre marzo-julio de 1947 y marzo de 1953 (muerte de Stalin) discurrió el período más duro de la Guerra Fría. Durante la Crisis de los Misiles quedó en evidencia que la guerra nuclear era una amenaza real. Y el director británico Stanley Kubrick hace responsable de su amenaza tanto a Estados Unidos como a la Unión Soviética. La Crisis de los Misiles tuvo consecuencias importantes. Aparte de precipitar la caída de Kruschev, la toma de conciencia del riesgo nuclear que se había corrido durante la crisis y que seguía existiendo en un mundo lleno de armas nucleares obligó a adoptar medidas concretas para limitarlo².

Una vena tragicómica permea quizá la película más famosa sobre la Guerra de Corea en la memoria reciente, MASH (1970) de Robert Altman. Algunos espectadores y críticos consideran La chaqueta metálica de Stanley Kubrick la mejor de la avalancha de películas contra la guerra centradas en Vietnam³.

\footnotetext{
1 “Guerra Fría”, en: Diccionario temático del cine / José Luis Sánchez Noriega. Madrid: Cátedra, 2004.

2 "La 'diplomacia atómica' en la Guerra Fría y Estados Unidos. ¿Teléfono rojo? Volamos hacia Moscú" / Coro Rubio Pobes, en: La historia a través del cine. Estados Unidos: una mirada a su imaginario colectivo. Bilbao: Universidad del País Vasco, 2016.

${ }^{3}$ Blockbusters. A Reference Guide to Film Genres / Mark A. Graves y F. Bruce Engle. Westport, Conn.: Greenwood, 2006.
} 
A diferencia de Misión to Moscow, La estrella del norte no es un panegírico de Stalin, sino un canto a la Revolución Bolchevique. La estrella del cine más famosa presente en Washington era Humphrey Bogart ${ }^{4}$. Muchos represaliados con la lista negra se habían convertido en exiliados. Pero, junto a Chaplin y Welles, el más célebre de los exiliados americanos en Europa fue sin duda Joseph Losey ${ }^{5}$. Arthur Miller y Lillian Hellman, quienes también ejercieron como guionistas cinematográficos, se situarían entre los proscritos de Hollywood con mayor prestigio. Losey no consumó su exilio hasta finales de $1952^{6}$.

El estallido de la Guerra de Corea en junio de 1950, con el consiguiente recrudecimiento del clima de Guerra Fría, precipitó el interés norteamericano de incluir a España en su plan de contención del comunismo en Europa Occidental. El hecho de que Estados Unidos se convirtiera en el principal aliado del régimen tuvo consecuencias determinantes en la imagen de la nación norteamericana en España ${ }^{7}$.

Uno de los géneros más interesantes que incorporó elementos anticomunistas durante la Guerra Fría fue la parodia. Hacia comienzos de los sesenta, las actitudes americanas hacia la Unión Soviética comenzaron a alterarse ${ }^{8}$. Oliver Stone ha trazado en media docena de películas los rasgos característicos de la sociedad americana desde la guerra de Vietnam hasta los años ochenta ${ }^{9}$. La experiencia personal de Stone en Vietnam domina sus tres películas sobre la guerra.

Losey fue a Inglaterra. De este modo se inició la carrera británica de Losey y Hollywood perdió a uno de sus más valiosos directores ${ }^{10}$.

\section{España, el franquismo y la Guerra Fría}

La primera visita de Frank Sinatra a España, cuando llegó a Barcelona persiguiendo a Ava Gardner en mayo de 1950, aconteció en el momento más bajo de su popularidad. Sinatra vino a buscarla varias veces, antes, durante y después de su separación. Era difícil para los directores de cine ${ }^{11}$. Tras la Guerra Civil, las películas norteamericanas se habían convertido en cultivo principal del divertimiento del pueblo. Los cines se multiplicaron. Frank y Ana eran deslumbrantes en América y en España. Tras la declaración oficial de la Guerra Fría, la dictadura negoció al alza el precio de España.

Barcelona, en este momento, es la ciudad en la que están presentes las majors de Hollywood, filiales nacionales de todas las grandes de la fábrica del cine. En diez años, España pasa del ostracismo a la incorporación escalonada en los organismos internacionales. Las nuevas circunstancias de Hollywood propiciaron rodajes fuera de los estudios, rodajes a gran escala, en países con costes de producción más competitivos y escenarios naturales de la fascinación. Las grandes multinacionales primero descubrieron la capital y luego el Paseo de la Castellana. Kramer, Mankiewicz y Preminger contaron con Sinatra, y todos sufrieron su carácter. En 1955, Ava Gardner

\footnotetext{
${ }^{4}$ Reynold Humphries: Las listas negras de Hollywood. Una historia cultural y política. Barcelona: Península, 2009.

5 Santiago Rubín de Celis: "Inglaterra como lugar de acogida del exilio de Hollywood", en: Listas negras en Hollywood. Radiografía de una persecución. Madrid: Universidad Complutense, 2009.

${ }^{6}$ Javier Coma: Las películas de la Caza de Brujas. Madrid: Notorius, 2007.

7 Daniel Fernández de Miguel: "La erosión del antiamericanismo conservador durante el franquismo", en: $L a$ ofensiva cultural norteamericana durante la Guerra Fría. Ayer, 75/2009 (3), pp. 13 - 221.

${ }^{8}$ Anti - Communism and Popular Culture in Mid - Century America / Sydney Hendershot. Jefferson, North Carolina: Mc Farland, 2003.

${ }^{9}$ R. A. Rosenstone: La historia en el cine. El cine sobre la historia. Madrid: Rialp, 2014.

${ }^{10}$ Román Gubern: La Caza de Brujas en Hollywood. $2^{\text {a }}$ ed. Barcelona: Anagrama, 1991.

${ }^{11}$ Francisco Reyero: Sinatra. Nunca volveré a ese maldito país. Sevilla: Fundación José Manuel Lara, 2015.
} 
decide trasladarse indefinidamente a España. El cantante siempre había admirado a Bogart. De su relación con Bogart nació su romance con Lauren Bacall. En esta época se sentaron las bases de las grandes filmaciones en España. Bronston supo extraer el jugo al régimen de Franco, que ya había comprobado las virtudes propagandísticas del cine norteamericano.

\section{EI Muro de Berlín, el espionaje y el cine de la época}

Uno, dos, tres tuvo mucho éxito, sobre todo en Alemania, después de caer el Muro. Uno, dos, tres se filmó por completo en Berlín y Múnich ${ }^{12}$. Berlín oriental aparece con solares en ruinas. El tercer hombre huele a la Viena de posguerra ${ }^{13}$. La pesimista visión de la vida característica del film noir era producto de esa filosofía del desengaño que se perpetúa a lo largo del período de incertidumbre nacido de la Segunda Guerra Mundial y que se dio en llamar Guerra Fría.

El factor humano es de 1980. La sobria y apasionante novela de Graham Greene, sobre un maduro agente doble inglés que se ve obligado a pasar a Moscú y abandonar a su familia, debió parecerle a Otto Preminger un material perfectamente adecuado ${ }^{14}$. Graham Greene (1904 - 1991) es el artífice de esta ingeniosa trama policíaca. Durante toda su vida mantuvo una estrecha colaboración con el mundo del cine. G. Greene ha trabajado asiduamente como guionista en adaptaciones de obras propias y ajenas. Además, la mayoría de sus novelas han sido adaptadas al cine, en ocasiones por grandes directores. C. Reed se ha valido de la obra del escritor en numerosas ocasiones, contando con él además de guionista. El escritor acabaría reconociendo con el tiempo que C. Reed fue el mejor adaptador de su obra literaria ${ }^{15}$. Lo que cuenta la película, la historia, anuncia la situación que desembocó en la construcción del muro de Berlín. La ciudad de Viena es protagonista sin duda de la película.

Cortina rasgada está inspirada en la desaparición de los dos diplomáticos ingleses, Burgess y Mc Lean, que abandonaron su país y se fueron a Rusia. Topaz era deliberadamente anticomunista y comportaba demasiadas escenas sarcásticas contra el régimen de Fidel Castro ${ }^{16}$.

\section{EI cine norteamericano y la guerra de Vietnam}

Surgieron inevitablemente films de temática y formas políticamente incorrectas ${ }^{17}$. Fuera de Estados Unidos, Vietnam se había convertido en uno de los temas preferidos de cineastas comprometidos. Las alusiones a la guerra empezaban a ser constantes en los films de los que luego se denominarían directores del New Hollywood. El cazador (Michael Cimino) haría la aproximación definitiva al problema de los veteranos, mientras que Apocalypse Now (Francis Ford Coppola) daría una visión inédita sobre el conflicto, muy crítica y personal. Coppola muestra la actitud de los norteamericanos que combatían.

\footnotetext{
${ }^{12}$ Cameron Crowe: Conversaciones con Billy Wilder. $3^{\mathrm{a}}$ ed. Madrid: Alianza, 2012.

${ }^{13}$ José Luis Garci: Noir. $3^{\text {a }}$ ed. rev. Madrid: Notorius, 2013.

${ }^{14}$ José de Diego: Otto Preminger. Madrid: T\&B, 2003.

${ }^{15} \mathrm{M}^{\mathrm{a}}$ Angeles Martínez: Mito, cine, literatura. Laberinto y caos en El tercer hombre. Sevilla: Alfar, 2006.

${ }^{16}$ François Truffaut: El cine según Hitchcock. $3^{\mathrm{a}}$ reimp. Madrid: Alianza, 1988.

${ }^{17}$ Angel Comas: Los fabulosos años del New Hollywood. Panorama de dos décadas de cine norteamericano (196483). Madrid: T \& B, 2009.
} 
En Juan XXIII. El Papa de la paz se habla de la Guerra Fría. Se menciona la construcción del Muro de Berlín. El cazador trata de la guerra de Vietnam. Las escenas de guerra en Vietnam son terribles por ambos bandos. Coppola guarda muchos puntos afines con Kubrick. Trumbo fue una de las víctimas de la "caza de brujas", viéndose obligado a filmar con seudónimo los guiones que escribió entre 1950 y $1960^{18}$.

\section{El cine norteamericano: parodia y Guerra Fría}

Durante todo 1960 y 1961 Kubrick estaba cada vez más decepcionado con América $^{19}$. En 1965, Kubrick dirigiría ¿Teléfono rojo? Volamos hacia Moscú. El film lleva la Guerra Fría entre rusos y norteamericanos al límite de sus consecuencias ${ }^{20}$. Trece días es una película de Roger Donaldson, con Kevin Costner de protagonista. Trata la crisis de los misiles con la Unión Soviética. Es el inicio de la ruptura diplomática entre Cuba y Estados Unidos. El espía que surgió del frío, de Martin Ritt, se basa en una novela de John Le Carré. Se inicia en el Berlín dividido de la Guerra Fría. La tapadera está también dirigida por Martin Ritt. Trata de la actividad contra el comunismo en los Estados Unidos después de la Segunda Guerra Mundial. Trabaja como actor Woody Allen. También se hace referencia a la Guerra Fría. La película es de 1976. En Los USA en zona rusa, película de televisión de 1994, fue director, guionista y actor. En 1971, Bananas cuenta con Woody Allen como director. El guion es de Woody Allen y Mickey Rose ${ }^{21}$. En 1976, Woody Allen actúa en The Front, de Martin Ritt ${ }^{22}$. Los USA en zona rusa (W. Allen, 1994) está datada en la época de John F. Kennedy. W. Allen trabaja como actor.

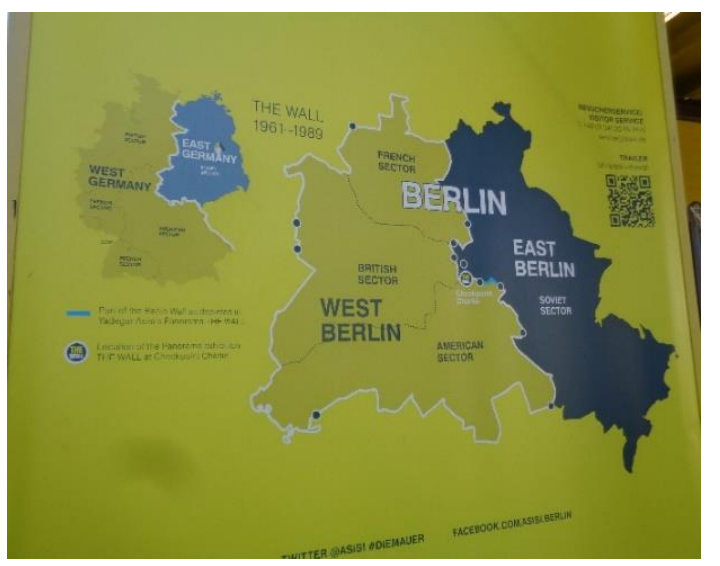

Mapa de Berlín dividido (Foto del autor).

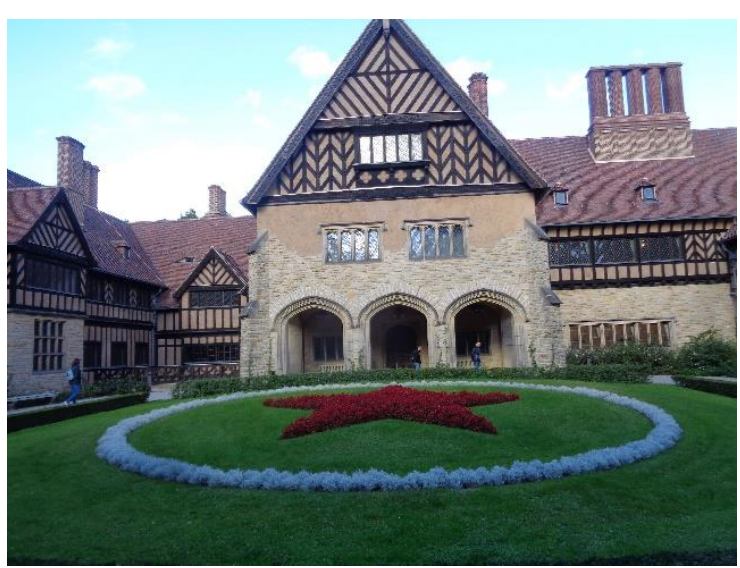

Palacio de Cecilia en Potsdam (Foto del autor)

\section{El cine de la izquierda norteamericana y la Guerra Fría. Spielberg y "EI puente de los espías"}

En Tal como éramos (Sydney Pollack), se habla de la guerra civil española y la ayuda rusa. Aparece una bandera con la hoz y el martillo de la URSS. Barbra cita a David Lean. Fue la película que consagró a Redford. La película se hizo en 1971. Se

\footnotetext{
${ }^{18}$ Juan Carlos Polo: Stanley Kubrick. Madrid: JC, 1986.

${ }^{19}$ John Baxter: Stanley Kubrick. Biografía. Madrid: T \& B, 2012.

${ }^{20}$ Esteve Riambau: Stanley Kubrick. $5^{\mathrm{a}}$ ed. Madrid: Cátedra, 2010.

${ }^{21}$ Jorge Ponte: Woody Allen. $6^{\mathrm{a}}$ ed. act. Madrid: Cátedra, 2012.

${ }^{22}$ Natalio Grueso: Woody Allen, el último genio. Barcelona: Plaza \& Janés, 2015.
} 
anuncia una fiesta ruso - americana y se ven las banderas de la URSS y Estados Unidos ondeando juntas. Redford y Pollack eran muy amigos. La película tuvo gran éxito y la música fue muy importante.

John Michael Frankenheimer nace en 1930. De los años 50 data su amistad con Robert Kennedy y su trato con la familia del futuro presidente John Fitzgerald. Sus opiniones en materia de política interior le llevan a deplorar el poder político y paramilitar de la CIA y el FBI. The Manchurian Candidate (El mensajero del miedo, 1962) se convierte en un éxito gigantesco ${ }^{23}$. Siete días de mayo se erige en el primer gran film del director y en uno de sus mejores trabajos ${ }^{24}$. El mensajero del miedo, de John Frankenheimer, se inicia en Corea en 1953. Se basa en una novela de Richard Condon. Termina la guerra de Corea.

Un ruso en Nueva York fue dirigida por Paul Mazurski. Robin Williams recuerda el himno de la URSS y su vida allí. La película es de 1984. En Indiana Jones y la calavera de cristal, los malos son los rusos. La película se inscribe en los años 50, en la época de la Guerra Fría.

En El puente de los espías (2015), drama histórico, Spielberg cuenta muy bien la historia de un hombre bueno y la empatía que se establece entre él y su defendido, exponiéndose a la ira pública contra un norteamericano que defiende a un comunista ${ }^{25}$. El relato está inspirado en hechos reales acontecidos durante los años calientes de la Guerra Fría. Sesgado en dos partes, un bloque que acontece a finales de los años 50 en Nueva York y otro a principios de los 60 en Berlín. La complicidad y el vínculo emocional que tiende Spielberg entre el letrado americano y el espía ruso comparten una vibración renoiriana ${ }^{26}$.

\section{Oliver Stone y la política exterior norteamericana}

Oliver Stone embarcó para Vietnam en septiembre de 1967, el día que cumplía 22 años. Cuando volvió a América, a fines de 1968, abandonó el mundo de los libros por el novedoso medio del cine ${ }^{27}$.

En noviembre de 1968 regresó a los Estados Unidos, pero la experiencia de la guerra le había marcado enormemente. Tuvo como profesor nada menos que a Martin Scorsese. Y rodó una de sus mejores películas, Platoon (1968), una cinta completamente antibélica pese a desarrollarse en la guerra de Vietnam. Su trabajo como director continuó a un ritmo frenético. JFK (1991) es la película que sin duda más le ha marcado. Entre 2003 y 2004 realizó tres documentales para la productora española Morena Films: Comandante (2003) - un interesante film sobre Fidel Castro -, Persona non grata - sobre el interminable conflicto palestino - israelí - y Looking for Fidel (2004), de nuevo basado en una larga entrevista con el dirigente cubano ${ }^{28}$.

La filmografía de Oliver Stone presenta dos caras muy distintas: por un lado, el artista comprometido políticamente y, por otro lado, una serie de películas mucho menos personales o reivindicativas. Dentro del primer grupo encontramos la trilogía dedicada a la guerra del Vietnam, así como las que se centraron en momentos políticamente claves de la historia de los Estados Unidos. Los dos documentales sobre

\footnotetext{
${ }^{23}$ Francisco Javier Urkijo: John Frankenheimer. Madrid: Cátedra, 2006.

24 "Un francotirador en Hollywood. John Frankenheimer" / por Tomás Fernández Valentí. Dirigido, Noviembre $2000, n^{\circ} 295$, pp. $48-71$.

${ }^{25}$ Carlos Boyero: "La Guerra Fría sin histeria”, El País, 4 diciembre 2015, p. 39.

${ }^{26}$ Carlos Reviriego: "Spielberg calienta la Guerra Fría". El Cultural, 4 diciembre 2015, pp. 42-44.

${ }^{27}$ Oliver Stone: El sueño de un niño. Madrid: Debate, 1998.

${ }^{28}$ Jorge Fonte: Oliver Stone. Madrid: Cátedra, 2008.
} 
Fidel Castro también entrarían dentro de este grupo. La principal constante en su cine es el realismo.

En 1986, dirige Salvador, con guion de Oliver Stone y Rick Boyle. Pero su proyección en los cines de los Estados Unidos tuvo muchos problemas. El discurso político que caracterizará al cine de Oliver Stone comenzó con esta película. En 1968 estrena también Platoon. Con dirección y guion de Oliver Stone. El guion de Stone se basó en sus propios recuerdos de la guerra, por lo que la mayoría de los hechos que allí se cuentan fueron reales. La película se rodó íntegramente en la selva de Filipinas. Nacido el 4 de julio (1989) fue dirigida por Oliver Stone, que escribió el guion junto a Ron Kovic. La música, de nuevo, es de John Williams. En 1991, JFK: caso abierto fue dirigida por Oliver Stone, con guion suyo y de Zachary Sklar. La música, de nuevo, es de John Williams. Tenemos a Kevin Costner en el que fue el papel de su vida. Se trata de la película más comprometida políticamente de Oliver Stone.

El cielo y la tierra (1993) cierra la trilogía que Oliver Stone ha realizado sobre la guerra del Vietnam, aunque esta vez se muestra la otra cara de la contienda. Comandante (2003) cuenta con dirección y guion de Oliver Stone. Es un retrato intimista y humano de Fidel Castro. En Looking for Fidel (2009, con guion y dirección del propio Stone, este regresó a la isla caribeña para realizar una nueva entrevista con Castro.

Nacido el 4 de julio trata sobre la guerra de Vietnam. Se ven protestas contra la intervención norteamericana en Vietnam. La música es de John Williams. La película trata sobre los años 50 y 60 , y sobre todo de los 70 y sus consecuencias.

\section{La comedia de la Guerra Fría y el maccarthismo}

En Operación UNCLE, se aborda un pasaje supuesto de la Guerra Fría en la época de Kennedy y Kruschev, en que dos agentes de USA y URSS colaboran para sacar de Alemania del Este a una espía británica. El tono de comedia es evidente.

En The Interview se cuenta un viaje de dos yankis a Corea del Norte, a los que se encarga matar al máximo dirigente. La película es de 2014.

Ave, César (Joel y Ethan Coen) es una parodia del cine clásico de Hollywood en sus diferentes géneros (de espionaje, musical...) y alude de forma cómica al "peligro comunista" en forma de un grupo de ejecutivos e intelectuales que trabajan para la URSS.

En 2005, George Clooney retomó el asunto de la "caza de brujas" en Estados Unidos para su magnífica película Buenas noches, buena suerte. A finales de 2015, Jay Roach ha filmado y estrenado el filme Trumbo (con guion de John Mc Namara) ${ }^{29}$.

En Marathon Man se habla de la persecución de Mc Carthy. Es una película de John Schlesinger.

En The Trotsky (Jacob Tierney), se habla de la guerra civil española y las Brigadas Internacionales. Se menciona Tierra y libertad. La película está rodada en Montreal, Québec. Y se estrenó en 2009.

\section{Las ciudades y el cine de la Guerra Fría}

En las últimas décadas, Praga ha sido una de las ciudades "camufladas" por excelencia. Otra ciudad centroeuropea que, recurrentemente, ha sido utilizada de este

\footnotetext{
${ }^{29}$ Leonardo Padura: “Trumbo, historia de los días del miedo". El País. Babelia, 25 marzo 2016, p. 9.
} 
modo es Budapest. Los vertiginosos y traumáticos cambios, destrucciones, reconstrucciones, divisiones, unificaciones, modificaciones y reinvenciones de una capital como Berlín a lo largo del siglo XX han encontrado en el cine un buen aliado testimonial. San Petersburgo es, para el cine, la gran ciudad ligada a $1917^{30}$.

En el nuevo siglo, nos conmueven películas como Good Bye, Lenin! (W. Becker, 2003). Más política y dura es La vida de los otros (Florian Henckel von Donnersmarck, 2006), muy premiada por mostrar los últimos años de la RDA y los tejemanejes de la Stasi ${ }^{31}$.

La Lisboa del espionaje se mantiene en filmes como La casa Rusia (Fred Schepisi, 1990), según la novela de John Le Carré ${ }^{32}$.

Desde las primeras imágenes cinematográficas, las tomas de las murallas del Kremlin, la Plaza Roja y el río Moscova se erigen en iconos de una ciudad por la que transitarán los protagonistas de El barbero de Siberia (Nikita Mijalkov, 1999). Basta recordar las prohibiciones de filmación durante la Guerra Fría para las producciones occidentales, que dieron lugar a que Guerra y paz (King Vidor, 1956), Doctor Zhivago (David Lean, 1965) o Gorky Park (Michael Apted, 1983) se rodaran en sus "dobles" cinematográficas. Se aprecia un lugar común: Finlandia, que perteneció a Rusia hasta 1918, como localización estelar. De signo bien distinto son otras películas que abordan esta temática desde entornos auténticos, como La casa Rusia o El círculo del poder. La casa Rusia será la primera producción norteamericana rodada en la Unión Soviética. El círculo del poder es la primera rodada en las dependencias de la KGB; La daga de Rasputín (Jesús Bonilla, 2011), la primera rodada en la Plaza Roja con permiso ${ }^{33}$.

De todas las cinematográficamente posibles, la Viena de la posguerra es la más carismática y popular gracias a El tercer hombre (1949). Todo en El tercer hombre es Orson Welles ${ }^{34}$.

\section{La Europa del Este, la izquierda occidental y el cine de la Guerra Fría}

Desde principios del siglo XX hasta el nuevo milenio, Moscú ha experimentado una expansión espacial frenética. En el caso del cine ruso, la plasmación de Moscú en el celuloide se hace bien presente en época soviética, en un contexto en que el régimen utilizó el medio como un valiosísimo instrumento de propaganda. El panorama actual post - soviético ha permitido la apertura al cine internacional, que ahora puede realizar su trabajo con mayor libertad en Rusia. Si duda, la época soviética es la que ha dejado, y sigue dejando, una mayor cantidad de cintas ambientadas en la ciudad del Moscova ${ }^{35}$.

La mitología de la revolución invadió buena parte de los países europeos. Andrzej Wajda es la poesía en el cine. El cine polaco experimentó un fuerte auge a partir de la finalización de la II Guerra Mundial ${ }^{36}$.

El cine polaco vivió un período de claro despegue a mediados de los años cincuenta. La práctica totalidad de los cineastas de la Europa oriental recibirían una sólida formación académica en diversas escuelas cinematográficas ${ }^{37}$.

\footnotetext{
30 "La ciudad en el cine. Entre la realidad y la ficción”, en: Francisco García Gómez y Gonzalo M. Pavés: Ciudades de cine. Madrid: Cátedra, 2014.

31 "Berlín. A vista de cámara" / Pilar Pedraza. Ibid.

32 "Lisboa. A ciudade que nunca existiu" / Angelica García - Manso. Ibid.

33 "Moscú. Historia, espías y ciencia ficción en la Plaza Roja" / Nekane Parejo. Ibid.

34 "Viena. La nostalgia de un mito" / Carlos A. Cuellar Alejandro. Ibid.

35 "Un paseo por el corazón de todas las Rusias: Visiones de Moscú en la pantalla” / Miguel Dávila Vargas Machuca, en: Ciudades europeas en el cine. Tres Cantos: Akal, 2013.

${ }^{36}$ Santiago Sánchez, Beatriz S. Sanz: La melancolía de la revolución. Panorama del cine europeo moderno. Madrid: Fragua,2006.
} 
Para los cineastas del Este, la Segunda Guerra Mundial constituye una verdadera obsesión, puesto que a sus consecuencias se debe la construcción de los respectivos estados socialistas. Heredero por la línea directa de los jóvenes desencantados del heroísmo bélico, el cine antimilitarista adquirió también una cierta relevancia internacional en el contexto de los "nuevos cines". El "nuevo cine italiano" polarizó en diversos frentes su compromiso político. El fenómeno del exilio adquirió características singulares en los países del Este. Es preciso señalar que también en el cine español se dieron casos de exilio. El compromiso político marcó también la trayectoria de otros cineastas. Es el caso, en Italia, de Bertolucci, de Bellocchio, de los Taviani o de Cavani.
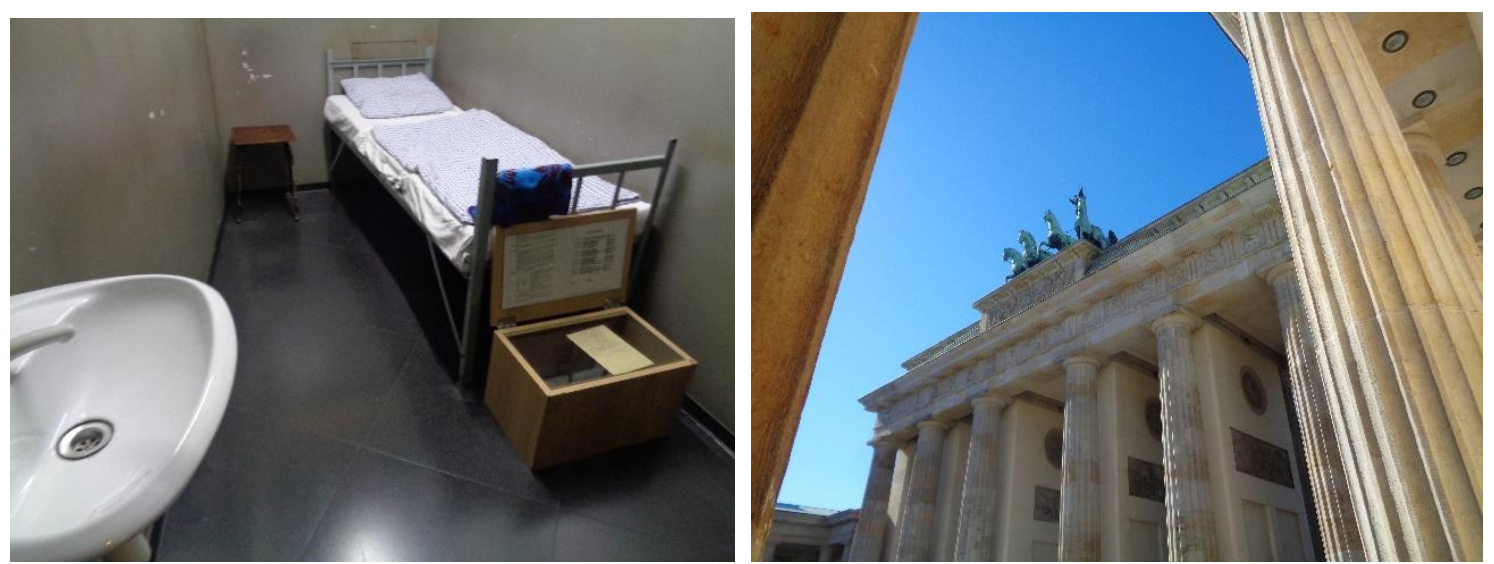

Izq. Celda del Museo de la RDA en Berlín. Dcha. Puerta de Brandenburgo en Berlín (Fotos del autor)

En este recorrido es preciso recordar el filme Pajaritos y pajarracos (1966). Una serie de cineastas entran en escena y con ellos una nueva generación de espectadores. El cine americano es la referencia cinéfila más directa de Wenders. Es necesario consignar aquí las fábulas políticas de los Taviani, volcadas hacia la revisión de la historia y el idilio con la utopía, realizadas entre 1971 y 1974. Frente al resto de sus compañeros de los Cahiers, solamente Godard se adherirá a la progresiva y no siempre clara politización de los sesenta, marcada por radicales tomas de posición ante las luchas anticoloniales y la guerra de Vietnam. En Europa, la relación cine - política toma rasgos distintos ${ }^{38}$.

Durante la década de los setenta, la coalición política entre socialdemócratas y liberales guiada por el canciller Willy Brandt transforma Alemania en una sociedad industrial y tecnológicamente avanzada. Paradójicamente, es en esta época de cambios cuando se advierte más nítidamente la pervivencia de signos autoritarios en la sociedad alemana, nacidos de la Guerra Fría, de la consolidación de la otra Alemania dividida por el Muro de Berlín. La cinematografía polaca suministra múltiples ejemplos de diáspora.

En Berlín Occidente (Billy Wilder), se ve el Berlín de posguerra, semidestruido. Se da la visión de los norteamericanos. Se observan el mercado negro, la Puerta de Brandemburgo... Es de 1948.

\footnotetext{
${ }^{37}$ José Enrique Monterde, Esteve Riambau: Los “nuevos cines” europeos, 1955 - 1970. Barcelona: Lerma, 1987.

${ }^{38}$ Doménec Font: Paisajes de la modernidad. Cine europeo, 1960 - 1980. Barcelona: Paidós, 2002.
} 


\section{Graham Greene y el cine}

Henry Graham Greene fue un novelista inglés, escritor de narraciones breves, guionista y periodista, cuyas novelas tratan problemas morales en el contexto de escenarios políticos. Greene es uno de los novelistas más leídos del siglo XX, un soberbio contador de historias. Aventura y suspense son elementos constantes en sus novelas y muchos de sus libros han sido hechos películas de éxito. Escribió cinco dramas y guiones para varias películas basadas en sus novelas. La estancia asiática estimuló El americano impasible (1955) de Greene, que trataba sobre el compromiso americano en Indochina ${ }^{39}$.

Graham Greene pertenecía a la primera generación de escritores británicos que crecieron con el cine. Y su obra fue profundamente influida por el nuevo medio. Prácticamente todas las novelas que escribió fueron llevadas al cine. La Guerra Fría es la expresión política de una profunda desconfianza mutua entre el bloque soviético y los poderes occidentales, y la causa de que se erigiese un elaborado sistema de espionaje, el mundo de los dobles agentes y los engaños que desde su adolescencia en adelante siempre fascinaron a Greene. Lo político es lo contrario de lo moral ${ }^{40}$.

El tercer hombre sigue guion de Graham Greene. Dirige Carol Reed. Viena está dividida en cuatro zonas. Es la posguerra y se ve la noria del Prater. El estraperlo está generalizado. Las patrullas por el centro eran multinacionales y el mercado negro y los ajustes de cuentas proliferaban. Conviven las formas clásicas de las fachadas con las ruinas de la guerra. La película es de 1949.

Nuestro hombre en La Habana está situada en Cuba antes de la Revolución y trabajan Alec Guinness, Noël Coward y Ralph Richardson. La dirigió también Carol Reed. Es de 1959. Es la época de la guerra civil en Cuba.

El americano impasible (1958, blanco y negro) se basa en la novela de Greene, adaptada y dirigida por J. L. Mankiewicz. Francia está en Vietnam y se lucha en el Norte con los comunistas. La acción transcurre en Saigón. Se narra en flash - back. La película fue rodada en Vietnam y en Roma. Hay otra versión de El americano impasible que comienza también en Saigón, en 1952. Es de Phillip Noyce, de 2002. El protagonista es Michael Caine. Las dos versiones se basan en la novela de Graham Greene, pero esta es en color. Francia pierde la guerra y ganan los comunistas. La película es más gráfica, presentando los muertos y los efectos de la guerra, los bombardeos... Esta segunda versión es algo más corta. Estados Unidos se instala en Vietnam para luchar contra los comunistas. El final es diferente. La película se rodó en Australia.

The Third Man es el único largometraje en el que Greene ha intervenido. Nació primero como tratamiento cinematográfico y como guion, y solo después fue publicado como novela breve. Los años treinta son para él de gran productividad. También a mitad de los treinta comienza a adentrarse en el mundo del cine. Entre 1947 y 1949, Greene alcanza su cenit como guionista ${ }^{41}$.

Su novela The Quiet Man (1955) parece una profecía acerca del futuro conflicto del Vietnam, igual que su caótica Our Man in Havana (1958) anticipa, de alguna manera, la crisis de los misiles. En 1973 publica The Honorary Consul, la novela que más le gustaba, según dirá en alguna ocasión. Durante su época como crítico de cine, Greene desarrolló su idea acerca del "cine poético". No basta con que una película represente la vida como es, sino también como debería ser. La última adaptación

\footnotetext{
39 (Henry) Graham Greene (1904 - 1991), file://A:Igreene.htm (29 / 07 / 02)

40 David Lodge: "Prólogo". Graham Greene: En tierra de nadie. Barcelona: Seix Barral, 2008.

${ }^{41}$ Enrique Fuster Cancio: El cine de Graham Greene. Madrid: Ediciones Internacionales Universitarias, 2008.
} 
cinematográfica de Greene producida hasta la fecha ha sido la versión de The Quiet Man dirigida en 2002 por el australiano Phillip Noyce, que conservó el título del libro. Se trata de una adaptación fiel tanto a la trama como al espíritu del texto.

La película The Third Man es un asunto de ingleses y rusos. La película se estrenó en Londres el 2 de septiembre de 1949, conquistando enseguida el favor de la crítica y el público europeo. The Third Man fue escrita para el cine. La capital austriaca ha sido destruida por las bombas y se halla en régimen de ocupación militar. El final de la película difiere del de la novela. En cierto modo, es un final abierto y ambiguo.

En El tercer hombre, la amistad, la traición, el amor imposible y la guerra son los temas propios del autor que Carol Reed, el cineasta, hizo suyos en su excelente película. En 1960 se rueda Nuestro hombre en La Habana, con guion de Greene sobre su propia novela y el protagonismo de Alec Guinness. La película, antes del bloqueo, pudo rodarse en exteriores naturales ${ }^{42}$.

Algunas de las novelas de Greene tienen el telón de fondo de la Guerra Fría. Se ha dicho de él que fue el maestro de John Le Carré ${ }^{43}$.

Durante cuarenta años, Berlín fue el símbolo más destacado de la Guerra Fría y la naturaleza dividida de Europa. En los 50, la ciudad fue el centro de tensión en la disputa Este - Oeste. Entre 1949, cuando la República Democrática Alemana fue formalmente constituida en Berlín Este como capital, y agosto de 1961, cuando el Muro de Berlín fue construido, hubo una constante hemorragia de "escapados" desde el Este $^{44}$.
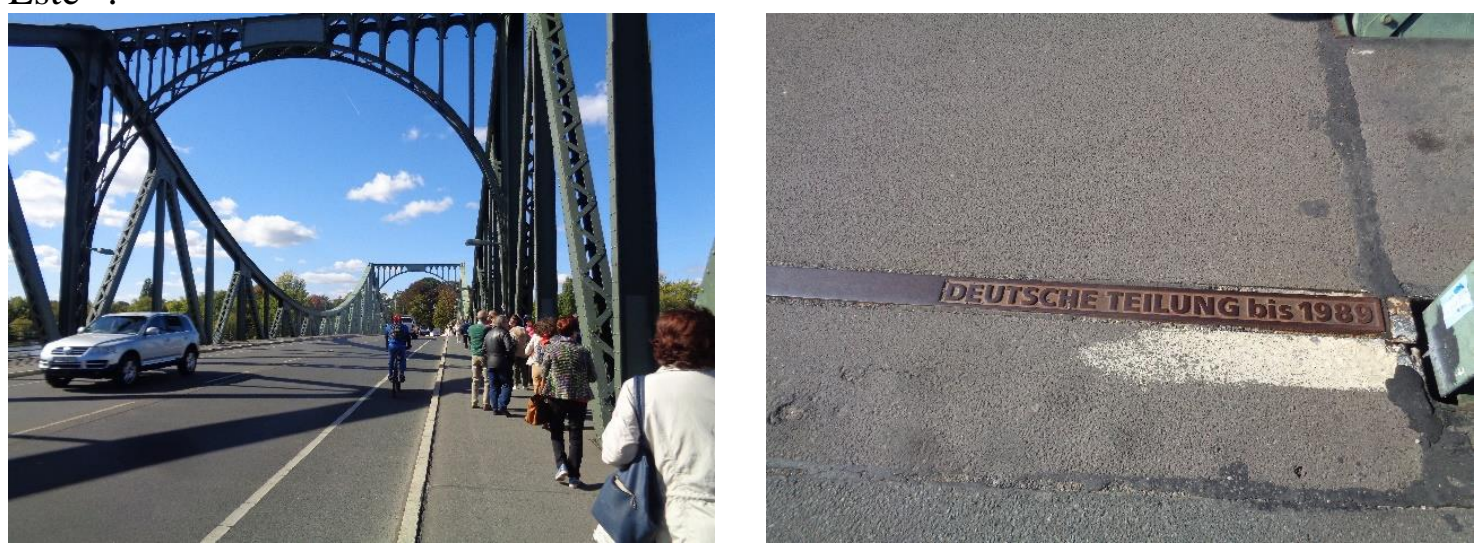

Izq. Puente de los Espías. Dcha. Frontera entre las dos Alemanias (Fotos del autor)

La década de los sesenta vio también nacer la infiltración de una mirada crítica sobre la actividad cotidiana del espía, a partir especialmente de la nueva narrativa de John Le Carré ${ }^{45}$.

El espionaje fílmico ha hecho del tren un centro de actividad preeminente. Encontramos trenes en multitud de films. En 1949, El tercer hombre, de Carol Reed, cuenta con guion de Graham Greene. Un guion original de Graham Greene da paso a una absorbente película de Carol Reed, a cuya filmación no es ajena la presencia de Orson Welles.

El espía que surgió del frío (1965), de Martin Ritt, cuenta con guion de Paul Delm y Guy Trosper, basado en la novela de John Le Carré. Impecable adaptación de la novela de John Le Carré y el retrato más desencantado que ha dado el cine al espionaje

\footnotetext{
${ }^{42}$ Juan Tébar: "Ciudades de Graham Greene". En Imágenes de la ciudad. II Curso de Cine y Literatura. Burgos: Universidad, 2003, pp. 87 - 94.

${ }^{43}$ Adolfo García Ortega: "Vagar por las calles", El Norte de Castilla, 25 enero 2014. La Sombra del Ciprés, p. 7.

${ }^{44}$ Tony Shaw: British Cinema and the Cold War: The State, Propaganda and Consensus.London: I.B. Tavis, 2001.

${ }^{45}$ Xavier Pérez: Películas clave del cine de espías. Teià (Barcelona): Robinbook, 2010.
} 
durante la Guerra Fría. En 1990, La casa Rusia, de Fred Schepisi, se basa en un guion de Tom Stoppard, según la novela de John Le Carré. Se trata de una adaptación de una novela de John Le Carré.

Como todos los grandes actores del género, Graham Greene (1904 - 1991) había trabajado para los servicios secretos. El factor humano (Otto Preminger) trata sobre el espionaje británico durante la Guerra Fría. La película es de 1979. El protagonista es agente doble de los soviéticos, pero no es comunista. Al final, se va a Moscú. Se basa en la novela de Graham Greene, con guion de Tom Stoppard.

\section{Joseph Losey y John Le Carré o la contribución del cine inglés}

Joseph Losey inició un viaje a Europa con la mirada puesta en un país concreto: la Unión Soviética. La estancia de Joseph Losey en la Unión Soviética fue una forma de aprendizaje y asimilación de una manera revolucionaria de entender el teatro que pronto tendría su aplicación en la escena norteamericana. A comienzos de 1945, Losey materializó sus ideales políticos afiliándose al Partido Comunista. Losey se embarcó, en el verano de 1953, hacia el que sería su destino definitivo: Gran Bretaña ${ }^{46}$.

El asesinato de Trotsky transcurre en México, 1940. Mientras Europa se halla en plena guerra, Leon Trotsky, uno de los principales líderes de la Revolución Soviética de 1917, está en el exilio en Coyoacán.

Los hombres de Smiley se basa en la obra de John Le Carré. Es de 1982. Trabaja como protagonista Alec Guinness.

\section{La URSS y la Guerra Fría}

La opinión de los críticos cinematográficos sobre El círculo del poder no fue, en términos generales, muy positiva. La película de Andrei Konchalovski, estrenada en España en 1991, aportaba como factor fundamental en su promoción comercial el ser la primera rodada en el Kremlin y en las dependencias del $\mathrm{KGB}^{47}$.

La disolución de la URSS en diciembre de 1991 puso fin a este período de 46 años denominado Guerra Fría. Fue a partir de 1948 cuando las tensiones entre los dos bloques llegaron a uno de sus puntos más álgidos. Berlín va a ser, sin duda alguna, el símbolo de la Guerra Fría y el motivo de las tensiones entre las dos potencias durante los primeros años de la misma. Este contexto hizo que las relaciones Este - Oeste, especialmente entre los Estados Unidos y la Unión Soviética, fueran cada vez más tensas. La década de los cincuenta fue decisiva para el desarrollo de las dos Alemanias, especialmente para la del oeste. Esta ciudad se convirtió de nuevo en el escenario donde se representaban los momentos más álgidos del enfrentamiento Este - Oeste. Berlín Occidente relata de una manera dura la vida de la ciudad alemana en los tiempos inmediatamente posteriores a la Segunda Guerra Mundial ${ }^{48}$.

Stalin era un gran aficionado al cine. La pasión de Stalin por las películas fue el tema principal de la película El círculo interior (1991), de Andrei Mijalkov Konchalovski. Con el inicio de la Guerra Fría, los directores de cine soviéticos

\footnotetext{
46 Joaquín Vallet: Joseph Losey. Madrid: Anaya, 2010.

47 Julio Montero: "El círculo del poder. Propaganda y represión en la Unión Soviética”, en: La historia a través del cine. La Unión Soviética. Bilbao: Universidad del País Vasco, 2001.

48 "Uno, dos, tres. Una visión de la guerra fría demasiado irónica para su tiempo" / Víctor Manuel Amado Castro. Ibid.
} 
comenzaron a crear películas antioccidentales como nunca antes. Algunas películas inconformistas retrataron a la juventud de formas radicalmente distintas ${ }^{49}$.

El año 1948 es, al menos en apariencia, el del reforzamiento de la dominación soviética en la Europa del Este, aquel en que, a pesar de los esfuerzos por prolongar la cooperación del tiempo de guerra, la Guerra Fría se desencadena. En 1951, la decisión de pasar al color comienza a ser aplicada a una gran escala. El estreno de la película de Kalatozov Cuando pasan las cigüeñas en octubre de 1957 marcó el comienzo de un período de transición en la historia del cine soviético ${ }^{50}$.

El renacimiento del cine soviético al final de los años cincuenta y al comienzo de los años sesenta tuvo por aliado más seguro la nueva literatura. Más que quizás en otra parte de la Unión Soviética, los talentos cinematográficos originales florecían en Georgia. El más conocido internacionalmente de los jóvenes realizadores georgianos fue sin duda Otar Iosseliani (1934). La misma época vio desarrollarse el talento irónico de Nikita Mijalkov (1945), hermano menor de Andrei Kontchalovski. Entre los realizadores de la generación de los años sesenta y setenta, Elem Klimov jugó un papel clave. Rodó Adiós a Matiora (1983) según una novela de Valentin Rasputin. Kontchalovski ha rodado la película modelo del período brezneviano, Siberíada (1978) y. pese a ello, ha podido ganar Hollywood provisto de un pasaporte soviético.

En Polonia, es otra vez Andrzej Wajda quien vino a agitar esta tranquilidad superficial. Jerzy Skolimovski está profundamente marcado por la experiencia del estalinismo y fascinado por todas las formas de revuelta. El retrato de Polonia que se derivaba de las películas de los años setenta no habría podido apenas ser más sombrío. La figura dominante entre los cineastas que sucedieron a la generación de Skolimowski y de Polanski fue la de Krzysztof Zanussi (1939). Andrzej Wajda dominó más que nunca el cine polaco.

En la década de los sesenta se introdujo una cierta relajación en todos los ámbitos de la política interior soviética. A finales de los años sesenta el cine histórico había aumentado en Hollywood. Pero tanto rusos como españoles también verían en este período histórico y en su representación cinematográfica un argumento para reforzar su propia identidad ${ }^{51}$.

Red Army se subtitula La Guerra Fría sobre hielo. El deporte servía como propaganda de los logros del sistema soviético. Desde 1986, la URSS no pudo competir con el Oeste. Las reformas de Gorbachov significaron el final de la Guerra Fría. La URSS se convirtió en Rusia, en 16 Estados independientes. Red Army es una película de Gabe Polsky.

\section{Wajda y el cine polaco}

El renacimiento nacional de los países del centro y este de Europa, tras las catástrofes de la Segunda Guerra Mundial, alcanza también al ámbito cinematográfico, por lo que en alguna medida tras la contienda surgen varias nuevas cinematografías. Será unos pocos años después, ya en la década de los cincuenta, cuando comienzan a

\footnotetext{
49 Dmitry Shlapentokh \& Vladimir Shlapentokh: Soviet Cinematography 1918 - 1991: ideological Conflict and social Reality. New York: Aldine De Gruyter, 1993.

${ }^{50}$ Mira y Antonim Liehm: Les cinémas de l'Est. Paris: Editions du Cerf, 1989.

${ }^{51}$ Enric Ruiz Gil: "El bicentenario de la batalla de Waterloo en el cine", FilmHistoria online. Vol. XXV, n². Año 2015 , pp. $23-37$.
} 
emerger ciertas disidencias o rupturas respecto al modelo cinematográfico oficial que serán la semilla de los "nuevos cines" de los países del Este ${ }^{52}$.

Por su desarrollo, destacan las cinematografías de Checoslovaquia, Hungría y Polonia. Cabe mencionar que la mayoría de los films que no se estrenaron antes llegaron a los cines durante los ochenta, en la era Gorbachov ${ }^{53}$.

Pero cuando aparecen Roman Polanski y Andrzej Wajda, la cinematografía polaca experimenta una auténtica renovación. El cine de Tarkovski se desarrolla en un momento particularmente tenso de la historia mundial, bajo el signo de la Guerra Fría y la amenaza nuclear ${ }^{54}$.

Wajda aparece definitivamente más cerca de la herencia romántica, de la tradición intelectual del país ${ }^{55}$.

El cine de los primeros años de la Perestroika no solo se contentó con la irrupción de una nueva generación, sino también con la consolidación de algunos nombres del cine soviético que empezaron a realizar películas más abiertas, algunas de gran espectacularidad. Andrei Konchalovski regresó tímidamente al cine ruso para dirigir una parábola sobre el proyeccionista de Stalin titulada El círculo del poder $(1991)^{56}$.

Los 70 trajeron un cambio considerable en el clima social, político y espiritual. El cine, también, fue afectado significativamente. Wajda filmó El hombre de mármol (estrenada en 1977), un proyecto que había estado contemplando durante catorce años y que significaba para él un viejo tema y un nuevo estilo ${ }^{57}$.

Se ha afirmado a menudo que la obra de Wajda contiene elementos de realismo socialista. Es algo inesperado descubrirlo en El hombre de hierro, realizada en 1981 durante el auge a cielo abierto de una Solidaridad que celebraba ${ }^{58}$.

Wajda obtuvo su mayor fama con las películas El hombre de mármol (1976) y El hombre de hierro (1981), un examen épico de la lucha entre el individuo y el Estado en la Polonia de postguerra que Wajda ha querido hacer durante años ${ }^{59}$.

El hombre de mármol trata de los problemas del trabajo socialista de una forma altamente crítica, y La tierra prometida es igualmente controvertida en su exploración de los comienzos de la industrialización de Polonia. En la segunda mitad de los 70, la situación política y social en Polonia cambió drásticamente. Una sociedad que había estado gozando de un período de relativa prosperidad experimentó un súbito deterioro en su modelo de vida. Una época de gran desorden comenzó en Polonia. Esta creciente inquietud se reflejó en las películas de la segunda parte de la década. En El hombre de mármol, Wajda describe los principales acontecimientos políticos en Polonia durante los años 50 y 60, terminando con la ola trascendente de huelgas que marcó una era de incertidumbre $\mathrm{y}$ lucha política durante los años siguientes. Estos mismos acontecimientos son más tarde aludidos en El hombre de hierro también. El film gozó de una popularidad no superada. A comienzos de los 80, Wajda decidió finalmente tomar una postura política decisiva.

\footnotetext{
52 José Enrique Monterde, Carlos Losilla: Introducción. Vientos del Este. Los nuevos cines en los países socialistas europeos, 1955 - 1975. Valencia: Filmoteca Española, 2006.

${ }^{53}$ Sara Markus: "Por qué en el Este fue distinto: rasgos comunes, hechos diferenciales". Ibid.

${ }^{54}$ Tamara Djermanovic: "Cruce de tradiciones, variedad de propuestas". Ibid.

${ }^{55}$ Fran Benavente y Santiago Fillol: "Del cero al infinito: entre lo cotidiano y lo metafísico en el nuevo cine del Este". Ibid.

56 Àngel Quintana: “¿Sigue existiendo cine en el Este?”. Ibid.

57 Boleslaw Michalek: "Visión de Andrzej Wajda del pasado y presente de un país", en: Politics, Art and Commitment in the East European Cinema. London: Macmillan, 1983.

${ }^{58}$ Paul Coates: The Red and the White. The Cinema of People's Poland. London: Wallflower Press, 2005.

59 Janina Falkowska: Andrzej Wajda. History, Politics and Nostalgia in Polish Cinema. New York. Bergham Books, 2007.
} 
El año 1989 marcó un período trascendental en la vida política y artística polaca, significando la abolición oficial del sistema socialista. Tradiciones de neorrealismo, documental, surrealismo y romanticismo informan la sensibilidad artística de Wajda, llegando juntas en sus primeras cuatro películas. Durante el deshielo, Polonia despertó de la pesadilla estalinista y comenzó el largo y penoso proceso de reconstrucción social y cultural. Los años 70 marcan el período creativo consumado de Wajda, durante el cual sus películas más altamente celebradas fueron realizadas. En El hombre de mármol, presenta acontecimientos políticos importantes ocurridos en Polonia durante los $50 \mathrm{y}$ 60.

El hombre de mármol (1977) está considerada parte de una trilogía junto con las películas El hombre de hierro y Danton. Las diferencias de clase, aunque oficialmente ausentes en la Polonia socialista, estaban sin embargo presentes en una sociedad donde la distribución de poder e influencia ya no dependían del origen familiar o de posesiones materiales, sino de la posición de uno en las filas del partido o de la relación con los dirigentes del partido.

Aquellas películas producidas por Wajda en los 70 constituyen la cima de su filmografía. Una secuela de El hombre de mármol, el retrato del presente alcanza su apogeo en El hombre de hierro (1981). Todas las películas producidas en los 80 eran política y socialmente importantes. La película de este período que tiene mayor fuerza política es El hombre de hierro. El hombre de mármol, Sin anestesia, El director de orquesta y El hombre de hierro son películas abiertamente políticas. Los 70 fueron una década de prosperidad económica y flexibilidad cultural en Polonia.

El tema de la guerra sería siempre una constante en la filmografía de Wajda. La década de 1970 fue la más fértil para Wajda. En 2007 realizaría Katyn, obra maestra que narraría la terrible matanza de oficiales polacos en el bosque ruso que da título a la película ${ }^{60}$.

Katyn (2007) se basó en Post mortem, una novela sobre el tema. La película comienza en septiembre de 1939. Los oficiales fueron asesinados en la primavera de 1940. En 1990, los soviéticos admitieron que los fusilamientos fueron obra de la NKVD.

Una corta jornada laboral (1981), de Kieslowski, trata de un dirigente comunista polaco que se enfrenta a los problemas a lo largo del tiempo. Sale a hablar con la gente. La policía apalea a manifestantes.

\section{El cine de la Europa socialista}

En Underground (Emir Kusturika), se trata de la Segunda Guerra Mundial en Yugoslavia, con la lucha entre nazis y comunistas. Belgrado es bombardeada por los nazis y más tarde por los aliados. La segunda parte se titula "La Guerra Fría". Emir Kusturika trabajó en El caso Farewell, una película que se desarrolla en Moscú y trata un tema de espionaje.

Forman perteneció a la generación dorada del cine checo, la llamada Nueva Ola checa. Tras la invasión de las tropas del Pacto de Varsovia en agosto de 1968, Forman se incorporó al llamado Nuevo Hollywood, que tuvo su momento álgido a comienzos de los 70. En Polonia, empieza a florecer la llamada Escuela Polaca. En 1962, el segundo deshielo llega a Checoslovaquia. Esto allana la aparición de la Nueva Ola Checa. Sin olvidar el boom literario, muchos de cuyos escritores trabajaron para el cine. Es el

60 "Biografía de Andrzej Wajda”, en: El hombre de mármol. Barcelona: Tribanda Pictures, 2010. 
comienzo en Checoslovaquia del desarrollo del que puede ser el tema principal en las artes de los antiguos países del Este: el conflicto entre el individuo y las autoridades. Este es, de hecho, el tema principal de las películas de Milos Forman (ya sean de su período checo o americano ${ }^{61}$.

\section{El exilio en el cine de la época de la Guerra Fría}

Al otro lado del muro trata sobre una exiliada de la RDA a Berlín Oeste.

Bardem había tratado en París a muchos de los represaliados por McCarthy refugiados en Europa. Norman Jewison aborda a menudo temas con carga social y política, pero dirigidos al gran público, como en su exitosa iQue vienen los rusos, que vienen los rusos! (1966), una sátira sobre la paranoia americana durante la Guerra Fría $^{62}$.

Muchos optaron por el exilio (como Bertolt Brecht, John Huston, Jules Dassin, Fritz Lang, Charles Chaplin, Joseph Losey...). Muy pocos se opusieron abiertamente ${ }^{63}$.

\section{El mundo del espionaje}

Durante sesenta años, USA y la URSS se enfrentaron. Entre el 53 y el 56 la guerra se hace abierta por el conflicto de Corea. La influencia de la Guerra Fría había llegado hasta Hitchcock. Hitchcock rodará Cortina rasgada (19669 y Topaz (1969) sobre el tema de los espías, pero son obras menores según la crítica. El tema del espía y el sexo están muy ligados. James Bond ha sobrevivido a la Guerra Fría. En los 60, surgen películas que intentan dar una imagen más realista del mundo de los espías. En los 60 y 70, se hace cine contra el poder. La comedia también sale en el mundo de los espías. El género paródico llegó hasta el fin de la Guerra Fría. Pero tuvo que adaptarse a las nuevas circunstancias. Matt Damon, Harrison Ford o Tom Hanks han hecho últimamente de espías. Ha habido clásicos como El topo (2011), basado en la obra de Le Carré. La vida de los otros se basó en el espionaje de la RDA. Ahora, estas películas tienen valor como fuente histórica ${ }^{64}$.

La acción de La vida de los otros se sitúa en Berlín - Este, en el año $1984^{65}$.

\section{España es diferente...}

Bienvenido, Mr. Marshall tuvo una extraordinaria acogida en el Festival de Cannes y ganó. El mundo de Bardem estaba unido a ese buen trabajo que es Bienvenido, Mr. Marshall ${ }^{6}$.

En 1952-1953, junto a Bardem y Miguel Molina, Luis Berlanga escribe el guion de su segundo largometraje, ¡Bienvenido, Mister Marshall! La película es una crítica, contada en clave de fábula, del Plan Marshall, al mismo tiempo que una radiografía

\footnotetext{
${ }^{61}$ César Ballester: Milos Forman. Madrid: Cátedra, 2007.

62 Amor López Jimeno: “Las tres vidas de Jules Dassin”. Amor López Jimeno (ed.): Las tres vidas de Jules Dassin (1911 - 2008). Del cine negro al nuevo Museo de la Acrópolis. Saarburcken: Editorial Académica Española, 2012.

${ }^{63}$ Elisa Ibáñez Orcajo: "El macartismo y la caza de brujas en Hollywood: Dassin en la lista negra". Ibid.

${ }^{64}$ Conferencia de José - Vidal Pelaz, 24 febrero 2014.

65 Tomás Domingo Moratalla: "Enredados en historias: una cuestión de responsabilidad. Reflexiones a partir de la película La vida de los otros", en: El ciudadano espectador. Derechos humanos y cine. Valladolid: Universidad Europea Miguel de Cervantes, 2012.

${ }^{66}$ Juan Eugenio Julio de Abajos de Pablos: Mis charlas con Juan Antonio Bardem. Valladolid: Quirón, 1996.
} 
cómica de la España rural. La película significa la revelación internacional de Berlanga. En 1956, se estrena Calabuch, una comedia rural narrada en tono de fábula ${ }^{67}$.

EDUARDO ALONSO FRANCH nació en Valladolid, en 1955. Licenciado en Historia General, Historia del Arte y Arqueología por la UVA, ha sido bibliotecario en la Facultad de Filosofía y Letras de la citada institución. Recientemente jubilado, ha publicado relatos y artículos sobre cine en diversas recopilaciones y revistas de Sevilla, Málaga, Zamora, Barcelona y su ciudad natal. Y también publicó en 2015 un artículo sobre la influencia de Doctor Zhivago en películas posteriores en la revista FILMHISTORIA ONLINE.

email— eduardo.alonso.franch@uva.es

67 “Crónica de una vida”, en: ¡Viva Berlanga! Madrid: Cátedra, 2009. 
FILMHISTORIA Online Vol. 29, núms. 1-2 (2019) · ISSN: 2014-668X 